\title{
Las disputas simbólicas por las culturas del agua. Agua y desarrollo sostenible en la Expo Zaragoza 2008
}

\section{Symbolic disputes on water cultures. Water and sustainable development in the Zaragoza Expo 2008}

doi: http://dx.doi.org/10.32870/

Susana Herrera Lima

espiral.v23i65.4458

\section{Resumen}

Este artículo estudia la transformación de los discursos sobre la relación entre sociedad y naturaleza en la modernidad a través de las exposiciones universales, en particular la Expo Zaragoza 2008, en la cual se muestra, desde el entramado de relaciones y procesos en torno a su constitución, su potencial-como dispositivo de visibilización y ocultamientopara observar y analizar la genealogía del discurso ambiental contemporáneo. El objetivo es dilucidar el papel de los discursos alternativos, contradiscursos y discursos ocultos, negociaciones y juegos de poder desde posiciones diferenciadas, en la elaboración del dispositivo de la Expo. Se concluye que la contienda por la hegemonía en los modelos de relación sociedad/naturaleza se expresa material y simbólicamente en la disputa simbólica por las culturas del agua librada en la Expo.

Palabras clave: culturas del agua, dispositivo, discurso dominante, discurso alternativo, exposiciones universales.

\begin{abstract}
This article studies the transformation of discourses on the relation between society and nature in modern times through universal exhibitions, in particular the Zaragoza Expo 2008, which shows, from the network of relations and processes concerning its creation, its potential-as a disseminating and concealment device - to observe and analyze the genealogy of the contemporary environmental discourse. The objective is to clarify the role of alternative discourses, counter discourses and hidden discourses, negotiations and power plays from differing positions, in the development of the Expo device. It concludes that the struggle for dominance in society/nature relationship models is expressed materialistically and symbolically in the symbolic dispute for water cultures given at the Expo.
\end{abstract}

Keywords: Water cultures, device, dominating discourse, alternative discourse, universal exhibitions.

-Profesora-Investigadora del Departamento de Estudios Socioculturales del Instituto Tecnológico y de Estudios Superiores de Occidente (ITESO). _ shl@iteso.mx 
Las exposiciones universales e internacionales del siglo XXI son herederas de una tradición de más de siglo y medio: sus orígenes se remontan al año de 1851, cuando se celebró la primera Gran Exposición de los Trabajos de la Industria de todas las Naciones en Londres, y se han venido realizando de manera casi ininterrumpida desde entonces. ${ }^{1}$ Este trabajo forma parte de una investigación amplia, centrada en la pregunta por las transformaciones en los discursos sobre la relación sociedad/naturaleza a lo largo de la modernidad, y cuyo escenario de observación han sido las exposiciones universales. ${ }^{2}$

En la ciudad de Zaragoza, durante el verano de 2008, confluyeron acciones y discursos sobre el agua en diversos escenarios, con visiones y propuestas en debate, en el contexto de una larga historia de luchas y disputas por las formas de acceso, distribución y gestión del agua en la región. Zaragoza, "la capital del agua", como propone el discurso oficial de la Expo Zaragoza 2008 (la Expo), lo fue desde múltiples ángulos y facetas, visibilizados y mostrados al público a través de la Expo, en un complejo juego de poder y tensiones no siempre visibles para el visitante de la exposición o el habitante de la ciudad.

En la Expo se abordó el tema del agua como elemento natural, como recurso y como derecho, como objeto de disputa y símbolo de encuentro, como problema insoslayable

I. Para una referencia histórica amplia y documentada de las exposiciones universales, se recomienda consultar la Encyclopedia of World's Fairs and Expositions, compilada por Findling (2008), y las obras de Rydell (I984 y 1993), Tenorio Trillo (1996) y Greenhalgh (201 I).

2. Las exposiciones se plantean como espacios de comunicación y representación del contexto sociocultural y de visión(es) del mundo, desde la perspectiva de un conjunto de actores dominantes en un momento histórico específico. Se sitúan como escenario de análisis de las propuestas discursivas de las naciones, corporaciones y organismos internacionales participantes. A través de sus exhibiciones y de los valores simbólicos que representan, se analiza su percepción y toma de postura respecto a las formas de relación entre sociedades y naturaleza a lo largo de un siglo y medio (ver: Herrera Lima -2015, en prensa-). 
en el mundo actual, vinculado a problemáticas de desarrollo y subsistencia. El objetivo específico en el análisis de esta exposición, en el marco de la investigación referida, fue dilucidar el papel de los discursos alternativos, los contradiscursos y los discursos ocultos, las negociaciones y los juegos de poder efectuados desde posiciones diferenciadas, y, especialmente, su intervención en la constitución y configuración del dispositivo Expo Zaragoza 2008. ${ }^{3}$ En los documentos oficiales, en la prensa, en sitios de internet y en las entrevistas realizadas fue posible identificar los conflictos y disputas, los desacuerdos y negociaciones alrededor del tema de la Expo, y particularmente sobre los diferentes énfasis y perspectivas que orientaron la forma de configurar y colocar un discurso que, no siempre con éxito, permitiera ocultar fisuras y visibilizar coincidencias entre las visiones e intereses de los diversos grupos que se incorporaron en el escenario.

Esta exposición es una muestra ejemplar del papel que juegan los discursos alternativos, que, aun cuando no aparecen explícitamente en los documentos oficiales de la Expo -o bien, se presentan reconfigurados e incorporados, ya sea como elementos subyacentes o como evidencias inocultables-, resultan piezas fundamentales en la conformación y articulación de las relaciones de poder que intervienen en la lógica estratégica que orienta y determina la constitución y configuración de un evento de carácter internacional, cuya función ha sido, a lo largo de más de un siglo, la legitimación y visibilización de un orden mundial por parte de los actores dominantes participantes: naciones, corporaciones y organizaciones internacionales.

3. En la investigación se ha mostrado cómo las exposiciones universales se constituyen y se configuran como dispositivos de visibilización de un orden mundial y de propuesta de modelos de mundo. El dispositivo es un concepto central en la propuesta teórico-metodológica, derivado de las formulaciones de Foucault sobre el mismo (Foucault, 1980, p. 195; Andersen, 2003; Castro, 2004). Ver: Herrera Lima (2013 y 2015 -en prensa-). 


\section{La constitución del dispositivo. Contexto y actores}

El objetivo fundamental en el análisis del proceso de constitución del dispositivo Expo Zaragoza fue dilucidar las condiciones socio-históricas que lo posibilitan y lo promueven, la determinación de la urgencia y los objetivos estratégicos que lo preceden. ${ }^{4} \mathrm{El}$ contexto local, regional, nacional e internacional previo a la realización de la Expo y el proceso de la candidatura (años 1999-2000) se desentraña a partir de documentos oficiales y de las entrevistas realizadas a dos actores clave: Francisco Pellicer, funcionario de la Expo, académico universitario y geógrafo experto en riberas, y Pedro Arrojo, fundador de la Fundación Nueva Cultura del Agua (FNCA), premio Goldman, científico, figura internacional de la problemática del agua, activista y asesor vinculado a movimientos sociales.

En el contexto político, la urgencia corresponde a la necesidad de la colocación a nivel internacional de la Comunidad Autónoma de Aragón y la ciudad de Zaragoza, para lo que fueron propuestas dos grandes iniciativas: un centro logístico de empresas y una exposición internacional. ${ }^{5}$ El objetivo manifiesto a nivel del Gobierno local era la transformación urbanística de la ciudad, según refiere Pellicer:

La idea de hacer una exposición internacional se concibe, en primer lugar, por parte de personas que están trabajando en el mundo de la política local, como un motor de transformación urbanística en la ciudad.

4. La caracterización y el análisis del dispositivo se elaboraron a partir de la articulación de las propuestas de Andersen (2003), Jäger (2003) y Castro (2004), que a su vez abrevan de Foucault (2009 y 20I0).

5. En Zaragoza se habían realizado ya exposiciones en el siglo XIX y la importante Exposición Hispano-francesa de 1908 (ver: Serrano Sanz, Gómez y Pérez y Pérez, 2009). 
Teníamos un proyecto que era el de restablecer un orden, la relación entre la ciudad y el río (entrevista personal, $20 \mathrm{l} \mathrm{Ia)}{ }^{6}$

El papel de "motores de transformación urbanística" atribuido a las exposiciones es una de las continuidades observables a lo largo de la historia de estos dispositivos: en cada una de las ciudades sede se ha colocado esta transformación como uno de los objetivos estratégicos centrales. ${ }^{7}$ En el panorama local de la ciudad de Zaragoza, la preocupación por la recuperación del río Ebro y por la transformación de la relación entre ciudad y río planteaba también la necesidad de modificar las percepciones que sobre el río tenían los habitantes de la ciudad:

[...] había que volver a enamorar la ciudad al río, que no podía ser que el río fuera aprovechado para sacarle el agua, para evacuar los desechos y permanecer abandonado, sucio, inseguro. [...] había miedo, al río se le tenía miedo, $[\ldots]$ había una especie de relación de que el río era peligroso, sucio, inseguro, en todos los aspectos, aspectos ambientales y aspectos sociales también (entrevista personal, 20l la).

La posibilidad de realizar una exposición internacional se vislumbraba entonces como una estrategia para conseguir recursos que permitieran orientar el programa de transformación urbana hacia la integración del río en la vida de la

6. Los documentos del corpus de la investigación están referidos en una tabla al final del documento.

7. La World's Columbian Exposition de 1893 situó a Chicago en la categoría de las grandes ciudades del Nuevo Mundo; las exposiciones del siglo XIX en París formaron parte del surgimiento de la ciudad de los pasajes de Walter Benjamin y de la urbe de los grandes boulevards, e incorporaron los íconos urbanos del París moderno, tendencia que se mantuvo durante todo el siglo $X X$, sentando las bases para el prototipo de la ciudad norteamericana de suburbios y highways que proponía el pabellón Futurama de General Motors en la world's fair de Nueva York en 1939. Esta relación entre el dispositivo y la ciudad sede se extiende hasta las décadas recientes con el reordenamiento de Sevilla para la exposición de 1992 y la gran transformación de la megalópolis de Shanghai para la exposición de 2010 (ver: Herrera Lima, 2015 -en prensa-). 
ciudad, a través de un plan de recuperación de las riberas. Por su parte, Arrojo da cuenta del contexto político más amplio en el que surge la iniciativa, donde es importante considerar la posición del Gobierno español, nacional y regional, respecto a las acciones políticas de los partidos en un periodo gobernado por la derecha en España:

El Partido Socialista prepara una estrategia de fondo para recuperar la iniciativa en ciertas capitales [...] lanza dos grandes iniciativas dentro de su estrategia de medio plazo de recuperar Aragón, y en particular la municipalidad de Zaragoza. Una es hacer de Zaragoza un centro logístico y atraer a las grandes empresas. $Y$ la otra es una Expo internacional, como parte del objetivo político de tener una iniciativa de envergadura (entrevista personal, 20l lb).

Las iniciativas de la recuperación de las riberas del Ebro y de buscar la candidatura para una exposición internacional fueron propuestas como parte del programa electoral del Partido Socialista en las elecciones municipales de 1999, y aunque los socialistas perdieron estas elecciones,

[...] la idea había cuajado y la gente se había ilusionado con la posibilidad de recuperar las riberas; era una cosa absolutamente necesaria y viendo que era posible obtener una exposición que fuera el motor de estas transformaciones (entrevista personal, 20l la).

En el libro que recoge la presentación de todos los elementos que se integraron en la solicitud de la candidatura ante el Bureau International des Expositions (BIE), ${ }^{8}$ se resalta, entre otros aspectos, la transición de España a un sistema democrático, su situación mundial como país de alto desarrollo y las características económicas y geográficas de 
la región de Aragón, su vínculo histórico con el agua y la diversidad ecológica de la cuenca del Ebro. En cuanto a la necesidad de recuperar el río y su integración a la vida de Zaragoza, se menciona el proyecto de acondicionamiento de las riberas del Ebro, cuyo objetivo sería "convertir el río en la calle principal de Zaragoza” (Bureau International des Expositions, 2004, p. 49).

El tema del agua es parte integral de la urgencia y el objetivo estratégico en la constitución del dispositivo. Cuando los Gobiernos de Zaragoza y Aragón buscaban la candidatura para la exposición internacional, no se tenía definido un tema, pero sí se tenía claro su posible papel en el proyecto de transformación urbana de la ciudad de Zaragoza. El proyecto de recuperación de las riberas del Ebro en la ciudad, como espacio público configurador de identidad y a la vez promotor de inversiones, resultó un elemento clave para la orientación y definición del tema en la candidatura. Se buscaba también una resignificación del río en la ciudad, una transformación intencionada en el imaginario de sus habitantes, desde la perspectiva de los actores políticos, como refiere Pellicer.

De tal manera que la coyuntura de la recuperación del río urbano, aunada a un conjunto de antecedentes históricos y características geográficas que vinculan a la región de Aragón con disputas y encuentros relacionados con el suministro y la posesión del agua desde la época en que fue asentamiento del Imperio romano y los tiempos en que el territorio fue dominio árabe, dieron lugar, desde la perspectiva de los Gobiernos locales, a proponer la temática más amplia de "el agua" como elemento único, insustituible e indispensable.

No hay una cosa que sustituya al agua. Es un recurso único, es una fuente de conflictos, pero sobre todo es un arma para la paz como pocas, hay muchos más acuerdos en torno al agua que guerras del [sic] 
agua [...] que el agua es un elemento cultural impresionante, que desde [hace] miles de años ha sido un instrumento para hacer civilizaciones (entrevista personal, 20l lb).

El proceso de decisiones en torno al tema de la exposición, referido desde la perspectiva de los organizadores, se sitúa en el ámbito de las condiciones de posibilidad para la constitución del dispositivo, hecho desde la vocación misma de las exposiciones como elementos de celebración y visibilización de logros, de avances y anticipación en la solución de problemas y conflictos en el marco del proyecto de la modernidad.

Por otra parte, está la evidencia de condiciones críticas a nivel mundial en la relación entre el ámbito urbano y los elementos naturales que también lo constituyen. La ciudad y el río en este caso, como representantes de una sociedad altamente tecnificada cuyos vínculos con la naturaleza se vuelven conflictivos, mostrando una indisociabilidad entre lo urbano y lo rural, lo natural y lo no natural: el río constreñido por el entorno urbano, contaminado y recluido, al que se confieren significados que lo muestran como un factor que pone en riesgo el bienestar de la población. Se propuso entonces a "el agua" como elemento de encuentro y conciliación; la "recuperación" de un río como símbolo de una relación de afecto y reciprocidad entre los procesos de producción y reproducción de las sociedades de la modernidad tardía y una naturaleza cada vez menos distinguible, cuya definición y delimitación resultaban crecientemente problemáticas.

Pero no bastaba hablar del agua, había que colocarla en términos del contexto mundial y las preocupaciones globales ya ineludibles: "vamos a hablar de agua y desarrollo y sostenibilidad [...] lo que el mundo quiere y necesita en tantos lugares, es que el agua se convierta en factor de 
desarrollo"9 (entrevista personal, 2011a). La confirmación de lo oportuno de esta temática llegó el 9 de diciembre de 2003, cuandolas Naciones Unidas declararon la década2005-2015Decenio Internacional del Agua para la Vida (Martínez Deaño, 2008).

Esta cuestión se vincula también con las recomendaciones del BIE en términos del tema de las exposiciones de los años recientes, destacando la necesidad de atender a problemáticas relacionadas con lo medioambiental y lo sostenible, como lo refiere el secretario general del BIE, Vicente González Loscertales, en un artículo periodístico: "Entre los tópicos adoptados por la Asamblea General en junio 8 de 1994, [está que] las futuras expos deben respetar el medioambiente y tender a convertirse en laboratorios de innovación y educación para el desarrollo sostenible” (González Loscertales, 2012).

El agua, como objeto discursivo principal, se significó en el discurso de la Expo como recurso único, como elemento insustituible para la vida y como factor de desarrollo sostenible. El discurso oficial sostenía, en palabras del alcalde de Zaragoza:

Zaragoza pensó en la importancia crítica que para todo el planeta tiene hoy el agua como recurso natural escaso, decisivo para la vida, crucial para el desarrollo [...] la pretensión fundamental es conseguir la concienciación social en valores como el ahorro, la solidaridad, el disfrute respetuoso y la responsabilidad (Belloch, 2008, p. 9).

El discurso dominante se encuentra comprometido, a nivel mundial, por las acciones que demandan los compromisos

9. Sostenibilidad y sustentabilidad son términos que en algunas regiones tienen diferentes connotaciones. Sin embargo, en España el término sostenibilidad es usado como sinónimo de sustentabilidad; tiene sus orígenes en las ciencias ecológicas y se convierte en objeto del discurso político y económico global a partir del informe Bruntland de 1987. El texto del informe puede consultarse en Naciones Unidas (s/f). 
políticos y económicos de los Gobiernos hacia las grandes corporaciones y el capital financiero, por una parte, y, en el otro extremo, con la imposibilidad de evadir la necesidad de considerar los problemas medioambientales planetarios y las demandas de los grupos y movimientos sociales. En el centro de esta tensión, como piedra clave y vínculo simbólico, se asienta contundentemente el desarrollo sostenible: el único deseable y el único posible.

Lograr el equilibrio entre las necesidades de progreso y las de preservación del medio ambiente es la base del desarrollo sostenible. Hoy por hoy, el único deseable y el único posible. Y el agua es, sin duda, un elemento central en cualquier consideración medioambiental y de progreso humano (Bureau International des Expositions, 2004, p. 52).

Entre las premisas del discurso oficial de la Expo se mantienen centralmente la unicidad del recurso y su papel indispensable para la vida y el desarrollo: una visión anclada en la concepción de la naturaleza como conjunto de recursos externos, a disposición del ser humano y sus necesidades, relacionada en primera instancia con lo que Giddens denomina la dimensión del industrialismo en la modernidad (Giddens, 2002), y actualizada en procesos de creciente mercantilización transnacional en la modernidad tardía; visión que a través de la incorporación estratégica de la sostenibilidad busca mostrar evidencias de una transformación en esta perspectiva, que transita de la certeza de la infinitud de los recursos y su disponibilidad para la explotación y uso humano, hacia una preocupación por la evidencia de sus límites.

Arrojo proporciona la dimensión sociopolítica del contexto en que se toman estas decisiones, y una visión alternativa a las motivaciones para la definición del tema. Señala el papel que juegan los movimientos sociales que se agrupan en torno a "la nueva cultura del agua", primero en Zaragoza 
y posteriormente en España, y la reconfiguración de fuerzas a partir del lanzamiento del plan de los grandes trasvases y el Plan Hidrológico Nacional, ${ }^{10}$ que surgen desde el Gobierno de derecha:

[...] El movimiento surge como un movimiento desamparado de apoyo político, al principio muy minoritario. Ya para los 2000 tiene una envergadura fuerte, ha supuesto contradicciones con [el] Partido Popular y con [el] Partido Socialista, pero ya no desde movilizaciones minoritarias, sino en manifestaciones de quince o veinte mil personas en Zaragoza [...] Con la ofensiva general de los grandes trasvases y el Plan Hidrológico Nacional se producen giros, esa labor que habíamos hecho con el Partido Socialista, con los sindicatos, empieza a fructificar de manera que sectores del Partido Socialista se empiezan a aliar. Se forman las plataformas ciudadanas de defensa del Ebro [...] En esos momentos conseguimos liderar, con el apoyo del Partido Socialista, con el apoyo de los sindicatos, movilizaciones súper masivas [...] (entrevista personal, 20l l b).

Estas acciones y alianzas, con los resultados visibles -en menos de un año consiguieron sacar a más de un millón de personas a la calle-, y el posicionamiento del Partido Socialista respecto a la problemática del agua, condujeron a tener que dotar de perfil a la exposición y proponer un tema, "pues la opción queda evidente, tiene que ser el agua" (entrevista personal, 2011b). Para ese momento, la nueva cultura del agua ha trascendido fronteras, con grandes

10. Los documentos oficiales del plan, propuesto en 200I, pueden consultarse en el sitio: http://chsegura.es/chs/planificacionydma/planhidrologiconacional/,y los análisis críticos y protestas, en La lluita per l'Ebre. El moviment social contra el Pla hidrològic nacional (La lucha por el Ebro. El movimiento social contra el Plan Hidrológico Nacional), un libro de diversos autores, publicado por Editorial Mediterrania en 2002, y en Avaluació crítica del Pla Hidrològic Nacional i proposta per a una gestió sostenible de l'aigua del Baix Ebre (Evaluación crítica del Plan Hidrológico Nacional y propuesta para una gestión sostenible del agua del Bajo Ebro), de Narcís Prats y Carles Ibáñez, publicado en Barcelona en 2003 por el Instituto de Estudios CatalanesSección de Ciencias Biológicas. 
contradicciones entre los discursos elaborados desde las diferentes posiciones de los actores en torno a lo que se concibe como "cultura del agua", que, de acuerdo a la FNCA, ${ }^{11}$ se entiende "como un cambio de paradigma hacia la sostenibilidad ambiental, económica, social y cultural, orientado a una consideración ecosistémica y patrimonial del agua" (Fundación Nueva Cultura del Agua, s/f). Sin embargo, se sitúa en el umbral de la necesidad por parte de Gobiernos y organismos internacionales de transformar el discurso ante los conflictos y movimientos sociales en torno al agua y los compromisos a nivel global con un sistema de gestión del agua mercantilista, inmerso en el modelo económico neoliberal. De tal manera que hubo un juego contradictorio en el que la nueva cultura del agua se incluía en el discurso oficial de la exposición o se eludía, dependiendo de las circunstancias y de los interlocutores.

Así que el tema agua es, y el tema sostenibilidad es, porque ya no puede ser de otra forma, ellos ya son conscientes en ese momento de que no puedes lanzar una Expo sobre el agua con "más regadío, más presas, más trasvases", etc. (entrevista personal, 20l Ib).

Lo que Arrojo refiere actualiza la histórica relación de la región de Aragón con el agua, vinculada en gran medida con su localización geográfica; esto coloca también en el ámbito de la geopolítica del agua a las condiciones históricas de posibilidad del dispositivo. Esta faceta del proceso de decisión sobre el tema de la Expo situaría a la disputa por las percepciones y visiones sobre la problemática del agua en el centro de las negociaciones entre los diferentes actores involucrados: partidos políticos, Gobiernos, organismos internacionales y movimientos sociales. El actor

II. En el sitio de la fundación (FNCA) pueden consultarse los principios que fundamentan las propuestas de la nueva cultura del agua, así como su organización, integrantes y acciones: http://www.fnca.eu/ 
oculto, pero con un peso determinante en las cambiantes inclinaciones de la balanza, sería representado por las corporaciones transnacionales involucradas en la construcción de infraestructura -presas, regadíos, minería, etc.-, gestión y privatización del agua, generación de desechos contaminantes, construcción de bienes raíces, actividades estas que inciden en la degradación del medioambiente en general, y particularmente en la situación problemática del agua a nivel global.

Las principales tensiones en la constitución del dispositivo se sitúan en el conflicto entre lo que Arrojo denomina los paradigmas de la antigua cultura del agua y la nueva cultura del agua: "Una visión antigua del agua como recurso, o una visión ecosistémica, de cooperación; una nueva visión que es solidaria, pero que debe respetar la naturaleza" (entrevista personal, 2011b).

Se identifican las visiones en disputa respecto a la naturaleza en general, y al agua, específicamente, como elemento representativo y vinculante de la relación con las sociedades humanas. Estos paradigmas se presentan como irreconciliables en la práctica desde la perspectiva de los movimientos sociales, pero en el discurso de la organización de la Expo mostrarían una postura de conciliación, colocada entre Gobiernos, organizaciones internacionales y corporaciones -como voces centrales en el discurso dominante- y los movimientos sociales. La sostenibilidad aparecería como bandera simbólica en la candidatura para la obtención de la Expo, y como concepto legitimador de prácticas se incorporaría al tema y lema de la Expo: "agua y desarrollo sostenible". Según Arrojo es un discurso disfrazado de nuevo, anclado en concepciones y visiones de la vieja cultura del agua, sin perspectiva política, "[...] son bien consientes [los organizadores] de que ya hay que empezar a cambiar el discurso, hay que hablar de sustentabilidad" (entrevista personal, 2011b). 
El 16 de diciembre de 2004, Zaragoza obtuvo el registro de exposición reconocida por el BIE, para realizar la Expo en el año de 2008 con el tema agua y desarrollo sostenible. La distinción entre antigua y nueva cultura del agua tomaría matices y mostraría intersecciones y traslapes a lo largo de los debates y negociaciones que tendrían lugar en la configuración del dispositivo entre los actores que confluirían en la Expo. Las variantes en los significados e interpretaciones atribuidas a la nueva cultura del agua se evidenciarían también en términos conflictivos en los discursos de los opositores a la Expo, que desde los márgenes contribuirían a la complejización del discurso normalizado de la sostenibilidad, y mostrarían las contradicciones entre las acciones que la organización del macroevento realizaría para "recuperar" el Ebro, y las repercusiones que estas tendrían en el ecosistema del cual el río forma parte, y en el que se incluye el mismo espacio urbano.

Diversos actores participaron en los procesos de decisión que culminaron en una exposición internacional en Zaragoza con la selección del tema del agua: 1) los partidos políticos, en un contexto de alternancia entre derecha e izquierda a nivel nacional y local, donde se jugaron posiciones de poder, situados en tensión entre los intereses de las corporaciones nacionales y transnacionales y la respuesta a demandas ciudadanas cuyos alcances también trascendieron el ámbito regional y nacional -con temas como los embalses del Pirineo, ${ }^{12}$ el pacto del agua, el regadío y las demandas de las corporaciones para llevar a cabo e intervenir en proyectos cuestionados públicamente por las organizaciones ciudadanas-; 2) los organizadores de la Expo y el BIE, con la colocación de un tema que vinculaba el contexto local y

12. Las presas (embalses) construidas en los ríos que descienden del Pirineo y que alimentan el Ebro han afectado los bienes y servicios ecológicos que estos proporcionan al río. Para una descripción amplia de estas afectaciones, ver:Nicolau Ibarra (2000). 
una preocupación mundial; 3) las corporaciones nacionales y transnacionales, con un papel protagónico en las disputas por la gestión y privatización del agua; 4) las organizaciones civiles, en el terreno de la lucha por los derechos sobre el agua y la justicia ambiental, un movimiento social en torno al agua que, como plantea Arrojo, surgió sin apoyo político, pero que creció en importancia y se consolidó en el movimiento nueva cultura del agua.

\section{La configuración del dispositivo.}

\section{Culturas del agua en disputa}

La Expo Zaragoza 2008 se realizó en el meandro de Ranillas de la ciudad de Zaragoza, España, del 14 de junio al 14 de septiembre de 2008. Fue clasificada por el BIE como exposición internacional reconocida. ${ }^{13}$ Se presentó al público visitante en un recinto de 25 hectáreas, acudieron ciento cuatro países, tres organismos internacionales, todas las comunidades y ciudades autónomas españolas (Expoagua Zaragoza 2008, 2008), seis socios patrocinadores y veintiún patrocinadores, y trescientas cuarenta y siete organizaciones no gubernamentales y movimientos sociales (Ecodes, s/f), que colocaron sus exhibiciones en los pabellones construidos por el país anfitrión con este fin -o, como en el caso de los grupos ciudadanos, en su propio pabellón-. España tenía un pabellón propio, además de los de Aragón y Zaragoza.

El tema "Agua y Sostenibilidad" se colocó y difundió en todo el recinto, en el escenario del meandro de Ranillas, en las riberas del Ebro, con los edificios y pabellones que

13. La diferencia de esta categoría respecto a la de otras exposiciones, las exposiciones mundiales registradas, está en la reglamentación: la superficie autorizada es de 25 hectáreas, la duración máxima es de solamente tres meses y es el país anfitrión el que construye el recinto y proporciona los espacios a los países y organizaciones invitados (B.I.E., s/f). 
aludían al agua tanto en su forma exterior como en las exhibiciones interiores. Las plazas temáticas fueron espacios al aire libre que abordaban diferentes aspectos del tema: sed, agua extrema, inspiraciones acuáticas, oikos, ciudades de agua y agua compartida; la Torre del Agua albergó la exposición Agua para la vida, constituyéndose en pabellón temático; el Pabellón Puente se presentó como una innovación arquitectónica y museográfica que se realizó en la estructura de un puente, construido como pabellón, que unía las dos riberas del Ebro para acceder al recinto de la Expo y que internamente fue un espacio de exhibición sobre el tema Agua, recurso único.

Una de las mayores innovaciones de esta Expo fue el Pabellón de Iniciativas Ciudadanas, "El Faro", donde se agruparon grupos independientes con diversas visiones alternativas sobre las problemáticas mundiales relacionadas con el agua, desde movimientos sociales hasta organizaciones no gubernamentales y dependencias de organismos internacionales, presentando una visión crítica de las posiciones de los mismos organizadores y participantes de la Expo (Viñuales y Fernández, s/f).

La articulación estratégica de todos estos elementos heterogéneos, entre los que se incluye de manera destacada el tema mismo de la exposición, dio lugar a la configuración del dispositivo Expo Zaragoza 2008, entre cuyas características y peculiaridades resalta el papel central que desempeñó lo que aquí se denomina y caracteriza como la disputa simbólica por las culturas del agua en la dinámica de discursos y relaciones que se establecieron entre los diversos actores participantes. Se abordan aquí dos escenarios de observación: el pabellón El Faro, al interior de la Expo, como espacio privilegiado de análisis de los debates, acuerdos y negociaciones en torno a las formas de significar y dar sentido a la problemática mundial del agua y sus múltiples vertientes y manifestaciones en territorios

\section{6}


localizados, cuyas propuestas discursivas se contrastan con las del espacio oficial de la Tribuna del Agua; y un espacio externo e independiente de la Expo, simultáneo y vinculado a esta por el tema y por la participación de algunos actores comunes, con énfasis en aspectos de orden social y político: el I Foro Mundial de las Luchas del Agua (FMLA), celebrado también en la ciudad de Zaragoza del 28 de junio al 6 de julio de $2008 .{ }^{14}$

\section{Los discursos de las culturas del agua}

La forma en que la sostenibilidad se presenta en el dispositivo evoca la imagen de la piedra clave de un arco, ${ }^{15}$ que busca equilibrar las posiciones entre el discurso identificado con una antigua cultura del agua, es decir, entre intereses abiertamente inclinados hacia el poder económico (transnacionales, corporaciones, organismos financieros), y el de la nueva cultura del agua, vinculada a intereses relacionados con el bienestar social (Gobiernos, partidos políticos, organizaciones civiles). Es un término al que acuden los discursos de las "culturas del agua" con distintas conceptualizaciones e intenciones, y atribuyéndole significados diferenciados. Las tensiones se presentan, tanto en las acciones como en los significados, entre aquellos que se identifican con la nueva cultura del agua y los que ellos nombran como representantes de la antigua cultura del agua. Estos últimos, los organizadores, nunca se autonombran o se identifican con esta faceta, más bien hacen explícitas

14. Los elementos fundamentales en el análisis de la lógica estratégica de configuración del dispositivo se abordaron desde las posiciones diferenciadas de los actores en la exposición, en relación con los elementos que lo constituyen y que se articulan estratégicamente: discursos, materialidades y prácticas. La estrategia analítica y los modelos que la integran pueden consultarse en Herrera Lima (20I 3 y 2015 -en prensa-).

15. Alusión a la piedra central de un arco arquitectónico, cuya función es equilibrar ambos lados en la estructura del arco. 
sus intenciones de afiliarse a posturas que promueven la sostenibilidad. Incluso se presentan como promotores de una nueva cultura del agua:

[...] estamos hablando de una nueva cultura del agua, [lo] que debe decir que hay que reflexionar y mirar también desde otros puntos de vista alternativos a las prácticas comunes del agua, llevadas, por ejemplo, por grandes empresas de ingeniería [...] Analicemos los fenómenos complejos y demos respuestas complejas a estructuras complejas (entrevista personal, 20l la).

En la práctica, en acciones externas y en la organización de la Expo se mantuvo una distancia conveniente del movimiento internacional representado por la FNCA, aunque este movimiento se convirtió, en los hechos, en un actor importante en la configuración del dispositivo.

El de la antigua cultura parecería ser un discurso que caduca, que no puede ya presentarse sin disfraces, pero que al mismo tiempo no puede perder vigencia en ciertos sectores, particularmente las corporaciones transnacionales y los organismos financieros internacionales, cuyos intereses están directamente vinculados a un modelo de relación que supone privilegiar el desarrollo económico a través de la innovación científico-tecnológica, y que supone también acciones de extracción y explotación de los llamados recursos naturales estratégicos. El traslape y la coexistencia conflictiva de los discursos de ambas culturas del agua evidencian la disputa permanente en los niveles material, político, económico y simbólico sobre el agua, cuestiones que en esta exposición se visibilizan y se ocultan, se disimulan y se exhiben, representando las tensiones globales a través de sus propias tensiones internas, mostrando así una de las continuidades de estos dispositivos, que buscan colocar y visibilizar un orden de las cosas, que en este caso, sin 
embargo, logra ser parcialmente subvertido por lo ineludible del discurso alternativo.

El pabellón El Faro, o "de Iniciativas Ciudadanas", es el vínculo de los discursos en conflicto, situado en permanente tensión entre la apertura y la crítica. El análisis de los discursos colocados ahí, como elemento simbólico y material de convergencias, negociaciones y diferencias, muestra las interrelaciones y traslapes entre ambas culturas del agua, la imposibilidad de establecer límites precisos entre una y otra postura, la importancia de la dimensión social y política que le confieren los movimientos sociales y, al mismo tiempo, la maleabilidad del término nueva cultura que, dependiendo del grado y forma de sus alianzas con el de sostenibilidad, representa intereses y formas de abordar la problemática del agua que apuntan a horizontes diametralmente opuestos.

[...] hubo otra experiencia muy interesante, fue con las organizaciones no gubernamentales. Participaron más de trescientas cincuenta organizaciones de los cinco continentes, es la primera vez que se ha hecho una cosa de esta naturaleza en una Expo, y se unieron organizaciones no gubernamentales de corte ambientalista y de cooperación para el desarrollo (entrevista personal, 20l la).

La presencia de las demandas de los grupos sociales, organizados en diversos movimientos y vinculados a la FNCA, es una cuestión ineludible en el conjunto de elementos a considerar para aproximarse a la comprensión de los procesos que intervinieron en la configuración de la exposición. El tema de la sostenibilidad y la experiencia de la Expo Aichi 2005, donde participaron ya algunas ONG japonesas, llevó a los organizadores considerar la posibilidad de incluir de alguna manera a ONG y grupos ciudadanos en la Expo Zaragoza. La dificultad estribaba en las formas de acercamiento y negociación de estos grupos desde la posición del organismo 
Expoagua, que organizaba oficialmente el macroevento, con sus compromisos institucionales inherentes -tanto con Gobiernos como con corporaciones-. Era necesario hablar de sostenibilidad, dar voces a los grupos ecologistas, pero a la vez mantener una distancia suficiente para prevenir la visibilidad de los conflictos ya existentes en torno a prácticas, acciones y percepciones sobre las problemáticas del agua entre los posibles participantes: países, corporaciones, organismos internacionales y grupos ciudadanos, movimientos sociales y ONG.

Pero las ONG no van a venir a los pabellones nacionales, muchas veces están en conflicto con sus propios países, y, si no, sólo van a venir las ONG que estén de acuerdo con sus Gobiernos y no va a haber una crítica y no va a haber visiones alternativas. Hay que crear un espacio independiente, en el que sea "el país de las ONG", el pabellón de las ONG, y además que trabajen juntos (entrevista personal, 20 I la).

El acercamiento de Expoagua a los grupos ciudadanos y ONG se hizo a través de la fundación Ecología y Desarrollo, un organismo cercano al Partido Socialista, la "parte verde" del partido, y su puente con el mundo de la ecología, con un discurso ambientalista, pero, a decir de Arrojo, "no necesariamente vinculado al significado político social de [la Fundación] Nueva Cultura del Agua" (entrevista personal, 2011b).

Sin embargo, la interlocución de Ecología y Desarrollo con los movimientos sociales se estableció a través de FNCA, particularmente a través de Arrojo, cuestión que lo colocó a él y a los representantes de la fundación en una posición en la que en primer lugar tenían que responder a la confianza de los movimientos sociales ambientalistas, que veían a la Expo como un tinglado de los Gobiernos, y a la vez aprovechar la oportunidad que proporcionaba un macroevento de esta naturaleza, con focos internacionales, dedicado al tema 
del agua, para visibilizar sus propias posiciones, causas y problemáticas, complejizando la muestra espectacular de logros científico-tecnológicos y políticos que se presentaría en la Expo.

La forma de participación de los movimientos ciudadanos se negoció de tal manera que ambas partes pusieron y aceptaron condiciones; al final, para unos fue símbolo de apertura y concesión:

[...] "y vosotros vais a poder debatir en completa libertad. Vais a poder hacer lo que sea". [...] entonces definieron su propio programa, sus propios temas, su propio funcionamiento, renunciaron todos a sus siglas y todo el programa de actividades lúdicas, de reuniones, de conferencias, de actos de todo tipo se desarrolló bajo un mismo lema. Se llamaban "El Faro", como un elemento, una referencia que ilumina y que marca trayectorias (entrevista personal, 20I la).

Mientras para otros fue muestra de conquista y fortaleza:

Acabamos poniendo por nuestra parte varias condiciones, una es que haya un pabellón ciudadano, que el pabellón sea absolutamente autónomo de la organización de la Expo [...] que la Expo no tenga derecho de veto sobre ninguna actividad que decidan los colectivos dentro del pabellón (entrevista personal, 20l lb).

Con la mediación de la FNCA, los arreglos se realizaron a través de un interlocutor que comprometía menos el discurso de la Expo, a la vez que atemperaba los posibles conflictos que podrían derivarse de una actitud de exclusión y segregación de movimientos socialmente posicionados y reconocidos. Estos, sin embargo, consiguieron por su parte irrumpir en el espacio de la Expo con su propio discurso, concediendo participar y aceptando los formatos delimitados por la organización, pero no renunciando a presentar posturas de franca crítica y oposición al discurso oficial 
propuesto por los otros actores en la misma exposición. Entre los movimientos, sin embargo, las posiciones tuvieron matices, hubo discrepancias sobre la conveniencia o no de participar: "es contradictorio y doloroso para ellos, porque es colaborar con el partido o con el Gobierno que les está haciendo las presas" (entrevista personal, 2011b).

En los fragmentos precedentes, son evidentes las dos posturas y visiones diferentes respecto a la participación de los movimientos sociales. Desde la representación de dichos movimientos se enuncian las condiciones que estos ponen para participar, y las dificultades para negociar la participación; desde la organización se relata como una iniciativa que busca colocar otras voces que pueden incluso disentir con los representantes de los países participantes. Desde una postura se habla del "Pabellón Ciudadano" y desde la otra es "el país de las ONG". Ambas nominaciones tienen connotaciones que es importante distinguir: los movimientos sociales se asocian a la resistencia y en este caso a la denuncia; las ONG se asocian a la institucionalización de las posiciones alternativas. El Pabellón Ciudadano hace alusión a la posición de un sujeto político, que puede participar y colocar sus posturas y demandas en este espacio. El país de las $O N G$, por su parte, despoja de cualquier connotación política y de resistencia al lugar, es una nominación idílica que apela a la ausencia de conflicto.

Surgió así el pabellón El Faro, redondo, opaco y ecologista, que no tenía aristas pero sí intersticios en el barro y paja de sus paredes curvas, que alojaban "la dimensión humana" de los conflictos y las luchas por el agua y los catapultaban como con un ariete al interior del dispositivo, fracturando de alguna manera la nitidez y el orden de su estructura, y obligando a la recomposición de sus elementos.

[...] y es verdad que de todas las cosas que se proponen, de todos los contenidos que se discuten, aunque muchos de ellos estaban en flagrante 
contradicción con lo que el Gobierno de Aragón hubiera dicho, a mí me consta que no hubo bloqueo o veto de ninguna de las iniciativas que fueron planteando aun los colectivos más radicales (entrevista personal, 20l lb).

El mensaje rector de El Faro era que el acceso al agua potable y saneamiento para todas las personas es un derecho humano, y proteger los ecosistemas acuáticos, una prioridad (Castro, 2009).

Este no es un pabellón de queja light y rosa, en donde el mundo es posible y no se sabe cómo; es de denuncia dura con alternativas que nos cuestan y allí están y muestran ese otro mundo posible y por qué es necesario. [...] esa combinación de denuncia, lucha y alternativas es lo que ha pretendido ser este pabellón, y en gran medida lo consiguió (Revista Aqua Vitae, 2008a, p. 50).

Derecho humano y protección a los ecosistemas son dos ejes que atravesaron la propuesta discursiva de El Faro: por un lado "la dimensión humana y la dimensión política", y, por otro, la visión ecosistémica que incorporó el componente científico, que a la vez que buscaba modificar la perspectiva que la ciencia moderna ha otorgado a la relación con la naturaleza en el contexto del capitalismo temprano y del modelo económico neoliberal, seguía, sin embargo, colocándolo como legitimador de las propuestas y posturas de los discursos alternativos.

El Faro fue también uno de los espacios de la Expo Zaragoza 2008 donde se congregaron las discusiones y reflexiones académicas y científicas que han sido sello distintivo de las exposiciones desde sus orígenes. Las reuniones de análisis y discusión que se desarrollaron en las doce "semanas Faro", estuvieron directamente vinculadas a las causas y luchas de los movimientos sociales relacionadas con el agua. Paralelamente, el espacio oficial para congregación de expertos 
científicos y técnicos de todo el mundo en el tema de la Expo fue la Tribuna del Agua, que inició sus trabajos desde junio de 2006 con un foro permanente en el que participaron organismos gubernamentales, expertos universitarios, compañías multinacionales y también asociaciones nacionales e internacionales. La Tribuna del Agua tuvo en la Expo su propio pabellón en el recinto, donde realizó diez semanas temáticas a manera de foros de discusión y debate, con la participación de doscientos veintiún conferencistas de cuarenta y siete países (Expoagua Zaragoza 2008, 2008).

Ambos espacios propusieron al cierre de sus trabajos documentos con conclusiones y recomendaciones: la Tribuna del Agua culminó en la Carta de Zaragoza; las semanas Faro presentaron cien conclusiones bajo el título de Legado de El Faro, y seleccionaron doce recomendaciones que fueron incluidas a su vez en la Carta de Zaragoza. Las fundaciones Nueva Cultura del Agua y Ecología y Desarrollo participaron tanto en las semanas Faro como en la Tribuna del Agua.

Desde ambos frentes se declaró que no había habido "competencia" entre los trabajos de la Tribuna del Agua y los de El Faro, y que habían sido más bien complementarios.

[...] vamos tomados de la mano y podemos tener diferencias, pero trabajamos en un tema que es fundamental. El Faro es dueño de una semilla que no debe perderse en ningún momento. El Faro es un acierto enorme de parte de la Expo, pero más acierto de las propias organizaciones que han sabido crearse un espacio en donde hay gobernabilidad dentro de su pluralidad. El Faro es un importante contenedor de asuntos que le dan gran trascendencia (Revista Aqua Vitae, 2008b, p. 43). ${ }^{16}$

16. Las palabras son del mexicano Eduardo Mestre, "un especialista en temas hidráulicos que ha dirigido la gestión de cuencas durante muchos años, y en los últimos tiempos ha colaborado en proyectos de gestión de diferentes países como Nicaragua, Sudáfrica o Nepal, además de trabajar para organismos como el Banco Mundial o la Unión Europea" (Tribuna del Agua, 2008). Fue el sucesor del español Domingo Jiménez Beltrán en la dirección de la Tribuna del Agua. Jiménez Beltrán había sido director de la Agencia Europea del Medio Ambiente. 
Sin embargo, hay elementos en disputa en uno y otro espacio. Por una parte, el ya comentado discurso de las culturas del agua, con referencia a procesos y relaciones de diferente índole y significados específicos para el concepto de sostenibilidad, aparece apropiado y con atribuciones de sentido diferenciadas. Las discusiones de El Faro, así como sus conclusiones y recomendaciones, privilegian lo que denominan la dimensión humana de los problemas del agua, visibilizando con ello las afectaciones y consecuencias que tienen las formas de concebir y relacionarse con el agua en los grupos humanos situados en posiciones de desventaja en las estructuras de poder. El cambio de paradigma respecto al agua se alude de manera insistente en ambas partes, con argumentaciones que parten del mismo origen, pero que derivan en propuestas que divergen en más de un aspecto: del agua como recurso o mercancía al agua como patrimonio mundial y derecho humano.

Los nuevos paradigmas sobre agua y sostenibilidad pretenden superar la visión meramente antropocéntrica para entender que, mediante una gestión integrada de los recursos hídricos, se protegen al mismo tiempo la supervivencia del ser humano y la del planeta (B. I. E., 2008).

La participación del sector privado en la gestión del agua fue cuestionada de manera frontal por los movimientos sociales, mostrando los problemas derivados de la creciente privatización de la gestión del agua a nivel mundial, argumentando la falta de transparencia en la gestión privada, el incumplimiento en los beneficios de retorno a las comunidades por parte de las empresas transnacionales y la situación de vulnerabilidad en que se colocan los ecosistemas ante la falta de control sobre la gestión, cuestión que deriva también en el desarrollo de infraestructura que provoca desequilibrios y degradación medioambiental (Castro, 2009). 
En la carta no hubo menciones específicas sobre la regulación de la construcción de presas o de los procesos de minería a cielo abierto. Se mencionó de manera general la necesidad de proteger los ecosistemas y se recomendó:

Que se definan modelos financieros solventes y con garantías, entre países e instituciones, de forma que permitan captar en el mercado capitales para inversiones en las infraestructuras hidráulicas necesarias para la prestación de los servicios públicos de abastecimiento y saneamiento, así como en la capacitación de los recursos humanos precisos (B. I. E., 2008).

El Faro recomendó explícitamente limitar y controlar la explotación comercial del agua (Castro, 2009), además de mostrar la complejidad de la problemática por la multiplicidad de actores que intervienen en su gestión, distribución, abastecimiento, saneamiento y legislación a niveles mundiales, regionales y locales. Dirigió sus recomendaciones también a los organismos internacionales:

El Fondo Monetario Internacional (FMI), el Banco Mundial (BM) y la Organización Mundial del Comercio (OMC) deben dejar de impulsar inapropiadas reformas de mercado para los servicios públicos a través de la condicionalidad de la ayuda, el asesoramiento técnico y los acuerdos comerciales (Castro, 2009, p. 14).

Los discursos de El Faro, sin embargo, no son homogéneos ni están exentos de posiciones en debate; agrupan organizaciones y movimientos con visiones críticas que se manifiestan en discursos que se derivan tanto de la diversidad de ámbitos de procedencia que confluyen en su configuración, como de la diversidad de intenciones que confluyen en un mismo espacio de representación; los ámbitos discursivos se intersectan y los significados que se atribuyen al agua y a la 
sostenibilidad se sitúan tanto en el ámbito discursivo de la justicia ambiental, como en el de la participación ciudadana.

La interdiscursividad al interior de la Expo se dio en un contexto de estrategias y dinámicas de visibilización y ocultamiento que intentó despojar a los discursos de tensiones en un contexto de aparente apertura a la disidencia. En este caso no fue posible "tapar todas las goteras": El Faro se constituyó como un gran ariete hecho de barro que consiguió irrumpir y colocar al interior de la Expo los discursos de la justicia, los derechos, la vulnerabilidad, la inequidad, la denuncia. Consiguió, asimismo, la colocación de los resultados de sus propios debates en forma de recomendaciones insertas en la Carta de Zaragoza. En síntesis, El Faro, Pabellón de Iniciativas Ciudadanas, se presentó en la exposición como un elemento que incidió desde varios ángulos en la lógica estratégica de configuración del dispositivo:

1. Como materialidad inserta en el espacio de la Expo, construida con elementos naturales no contaminantes, barro y paja, que son además reguladores de temperatura y humedad. El diseño integró elementos simbólicos -era un "botijo" o vasija - que refirieron a la cultura tradicional local.

2. Como configurador, emisor y depositario de discursos alternativos, difusor de las posturas, visiones y luchas de los movimientos sociales internacionales y del paradigma de la nueva cultura del agua; a la vez, como espacio de contención de estos discursos, donde pudieron ser delimitados y distinguidos, conviviendo con las propuestas del discurso dominante que lo rodeaban.

3. Como promotor y demandante de prácticas derivadas de la nueva cultura del agua, en ámbitos económicos, políticos, sociales y culturales a nivel mundial:

El Faro fue la primera vez en el mundo en que las organizaciones sociales compartieron mensaje y voz única aunque diversa, se autogestionaron, 
mantuvieron su independencia y pensamiento crítico y diluyeron sus logos para mantener su esencia y sumar esfuerzos (Castro, 2009, p. 10).

En la lógica estratégica para articular discursos, materialidades y prácticas, se identifican las estrategias del aparato de la Expo para incorporar los discursos ecologistas y una aparente visión ecosistémica; la transformación de las demandas y reivindicaciones y su incorporación en un discurso que no puede ignorarlas, pero que finalmente busca excluir a los movimientos sociales de la arena donde se dirimen los conflictos y se toman las decisiones de orden político y económico que les atañen, ocultarlos y subsumir las tensiones y contradicciones. El objeto discursivo "sostenibilidad" se constituye en un recurso del discurso dominante para resolver el conflicto entre la visión antigua y la necesidad de presentar una postura "sostenible" y "ecologista" que no arriesgue los compromisos políticos con actores sociales en conflicto.

Las estrategias de los grupos ecologistas y los movimientos sociales se incorporan en el discurso de la Expo con una perspectiva alternativa y una actitud crítica hacia los planteamientos que integran el discurso oficial y hacia la misma Expo. La visibilización de los conflictos y las tensiones a nivel mundial en relación al agua modifican las formas y los contenidos de los discursos oficiales de la Expo, obligando a colocar problemáticas de orden global como la escasez, el saneamiento y el abastecimiento, cuestiones que, sin embargo, se muestran como procesos en vías de ser resueltos, o cuya solución es factible a partir de acciones de orden científico-técnico, en primera instancia, y de decisiones político-económicas en dependencia de aquellas. Es decir, se muestra la problemática, pero se desactiva el conflicto. 


\title{
El discurso de la resistencia fuera de la Expo
}

Fuera de la Expo, simultáneamente, se realizó durante una semana el I Foro Mundial de las Luchas del Agua (FMLA), organizado por la Coordinadora de Afectados por Grandes Embalses y Trasvases (COAGRET),${ }^{17}$ en el que participaron afectados por problemas ambientales relacionados con el agua y también algunos de los personajes invitados por El Faro. En este foro, "se trata de poner cara a la cifra de 20000 muertos cada día por problemas de acceso al agua" (Foro Mundial de las Luchas del Agua, 2008). El evento se realizó explícitamente como lugar de crítica y desafío, de denuncias y formulación de rupturas: "Líderes sociales de todo el mundo en la lucha por el agua mostrarán en Zaragoza "la otra verdad que no se ve en la Expo", fue el título del post de la página Foro Mundial de las Luchas del Agua del 23 de junio de 2008.

\begin{abstract}
Durante nueve intensos días, se reunieron en la capital aragonesa gentes de todo el mundo con una historia común: todos ellos eran afectados por problemas derivados de las graves agresiones que el hombre inflige a los ríos y todos consagran buena parte de sus vidas a luchar en defensa de sus derechos, los de sus comunidades y los de su territorio (Menjón, 2008).
\end{abstract}

En el FMLA se denunció la invisibilización de los afectados por decisiones y acciones sobre el agua, que van desde la gestión y distribución, el acceso y la privatización, hasta los desplazamientos forzados, los derechos vulnerados y las migraciones ambientales. Se denunciaron también

17. La COAGRET se constituyó en 1995 como "una confederación de comarcas, pueblos y gentes afectadas por las grandes obras hidráulicas -realizadas, en construcción o en proyecto- dentro del territorio español" (COAGRET, s/f). Está integrada por organizaciones civiles, movimientos sociales y colaboradores independientes. La información puede ampliarse en el sitio: www.coagret.com 
prácticas de represión violenta y criminalización que colocaron a los grupos sociales en una situación de múltiple vulnerabilidad, tanto en términos de su ya precaria situación socioambiental -que da lugar a las luchas y protestas-, como de la percepción social que sobre ellos promueven los discursos de Gobiernos, corporaciones multinacionales y medios de comunicación. Se presentaron conceptos radicales como el "holocausto hídrico", y se señalaron los vínculos de las decisiones y acciones políticas y económicas con la degradación del ecosistema.

Este acontecimiento “sin precedentes” reunirá en Zaragoza a representantes de medio centenar de movimientos sociales con el denominador común de defender una lucha por el agua basada en los principios de sostenibilidad, equidad y participación ciudadana (Foro Mundial de las Luchas del Agua, 2008).

Se estableció una clara y frontal denuncia de procesos, acciones y omisiones, particularmente hacia las grandes multinacionales: contaminación del agua con cianuro y metales pesados por la minería de oro a cielo abierto, especialmente en América Latina y África; degradación de ecosistemas y contaminación de mantos acuíferos por procesos productivos y extractivos; expulsión forzada y sin indemnización por construcción de grandes embalses y presas hidroeléctricas; así como perjuicio a labores agrícolas y de pesca por los trasvases orientados a beneficiar a la industria turística a gran escala.

El discurso del FMLA asocia la sostenibilidad a la equidad y a la participación ciudadana, incorporando factores de orden político que buscan trascender la vinculación del término al mero desarrollo económico. En este caso, la enunciación procede fundamentalmente de los afectados por los problemas hídricos en diversas regiones del mundo. 


\section{El discurso de oposición a la Expo}

En los meses previos y durante su realización, surgieron movimientos en oposición directa a la Expo, comola Plataforma Ciudadana Contra la Expo 2008y No a la Expo, y se manifestaron también en su contra algunas organizaciones ambientalistas, como Green Peace, y algunas organizaciones ciudadanas como Grupos Autogestionados de Konsumo (GAK) y Ecologistas en Acción: "El sueño de la Expo encierra una pesadilla de avaricia, megalomanía, hormigón y autoritarismo" (La Garbancita Ecológica, 2008). ${ }^{18}$

En 2004, la Plataforma Ciudadana Contra la Expo 2008 se manifestó en el centro de la ciudad colgando una pancarta de 25 metros de longitud con el lema "Expo=Especulación". Ya entonces denunciaban "la agresión cementera a nuestras vidas y a nuestro mejor patrimonio natural" (La Garbancita Ecológica, 2008), derivada de los grandes intereses económicos, y lo que llamaban la fiebre partidista de captura de votos en torno a la búsqueda de la sede de la Expo. En diciembre de 2004, con esta y otras acciones, rompieron lo que llamaron "el silencio mediático comprado por los patrocinadores de la Expo" (La Garbancita Ecológica, 2008) y "la ocultación de las voces críticas" (La Garbancita Ecológica, 2008).

Las críticas en contra del macroevento que "se suma al proceso de modernización capitalista de la economía española" (La Garbancita Ecológica, 2008), alcanzaban a todos los participantes, particularmente a las transnacionales responsables de "violaciones sistemáticas de derechos humanos en relación con el agua” (La Garbancita Ecológica, 2008) y a los organizadores que hacen alianzas con las multinacionales que privatizan el agua; señalaban,

18. Las citas textuales de esta sección corresponden a la entrada "Desenmascaremos Zaragoza” de la página La Garbancita Ecológica (La Garbancita Ecológica, 2008). El sitio donde se encontraba la declaración completa de la Plataforma Ciudadana Contra la Expo: No a la Expo ya no está disponible. 
asimismo, la legitimidad que le confería la participación de organizaciones no gubernamentales y organizaciones “eco-neoliberales" (La Garbancita Ecológica, 2008).

Las denuncias puntuales sobre los costos sociales y medioambientales irreversibles situaron a la Expo en la "emergente industria del macroevento" (La Garbancita Ecológica, 2008) que, entre otras cosas, promovió "la reproducción de un modelo de cultura-espectáculo elitista, propagandístico y mercantilista" (La Garbancita Ecológica, 2008). Sus críticas pusieron en evidencia las contradicciones entre lo que llamaron la realidad de la Expo y el lema "agua y desarrollo sostenible":

Elimina huertas y encorseta el Ebro entre infraestructuras megalómanas que nada tienen de sostenibles. [...] Profundiza la brecha entre campociudad y entre integrados-excluidos. Embellece a las multinacionales del aguanegocio [sic] que se apropian del agua de las comunidades más pobres del mundo para vendérsela en forma de servicios potabilizados. El apoyo del Foro por una Nueva Cultura del Agua viste de sostenibles y solidarias las conclusiones de este macroevento, avaladas por el Banco Mundial, y legitima las políticas de privatización del agua de las próximas décadas (La Garbancita Ecológica, 2008).

Estos discursos se situaron en el extremo más radical de crítica a la Expo Zaragoza, denunciando el conjunto de alianzas e intereses entre los actores que configuraron el discurso dominante que ahí se colocó, y adoptando una postura de descalificación y rechazo para los grupos y organizaciones sociales que aceptaron participar al interior de la Expo.

\section{Discursos en contienda y contradicciones estructurales}

El análisis de los diferentes tipos de discursos que convergieron en la configuración del dispositivo y de la lógica estratégica que los articuló en el marco de las condiciones 
de posibilidad en que se negociaron formas y contenidos, significados y orientaciones, devela la complejidad de las visiones que subyacen en el espacio de negociaciones en que se constituye y se despliega. Permite, asimismo, mostrar que no se trata solamente de dos grupos con visiones homogéneas encontradas, sino de múltiples intereses, causas y percepciones que se expresan tanto en alianzas como en rupturas al interior de los diversos grupos de actores participantes.

Los principales objetos discursivos construidos en la Expo adquieren significados diferenciados en los dos grandes tipos de discursos analizados, el dominante y el alternativo: el agua, la sostenibilidad, la gestión, lo científico. Estas diferencias en la forma de significar el agua y la sostenibilidad no es menor y orienta al análisis de la contienda por la hegemonía de los modelos de relación sociedad/naturaleza, que se expresan discursivamente en las culturas del agua, y cuyas propuestas se muestran como irreconciliables, pero que coexisten y se traslapan tanto en declaraciones como en políticas y acciones.

Esta tensión, que suele referirse como una transición entre paradigmas, obliga a una discusión más amplia en relación a los presupuestos del capitalismo corporativo global y a las contradicciones estructurales de este (Giddens, 2002; Wallerstein, 2011), apuntando hacia el cuestionamiento por la factibilidad de transitar hacia una relación con lo medioambiental cualitativamente diferente en el contexto de este modelo económico o sistema-mundo, cuestión que llevaría también a la pregunta por el vaciamiento simbólico de términos como sostenibilidad y ecología, a partir de la resignificación de que son objeto tanto en el ámbito político a nivel de países y de organismos internacionales, como en el mercantil y mediático, a partir de la institucionalización del problema medioambiental. 
Al final, el legado de la Expo para la ciudad de Zaragoza tiene múltiples facetas: desde los reclamos por la transformación del meandro de Ranillas y el dispendio en la construcción del recinto, hasta la recuperación efectiva de las riberas del Ebro que se integran al espacio público de la ciudad.

El río se resignifica a través de la práctica en el centro de la vida cotidiana de los habitantes de Zaragoza; se incorpora como espacio de actividades de toda índole: religiosas, deportivas, artísticas, de reunión y de expresión. La visita presencial a los vestigios de la Expo y a la ciudad misma, en 2011, previa a las entrevistas con Pellicer y Arrojo, muestra a las riberas y al río "expuestos" para una observación del entorno: junto a los pabellones y plazas del recinto, ahora fantasmas de la exposición, que todavía esperan el final de las crisis sucesivas, globales y locales, para ser reutilizados, circulan los peatones y ciclistas zaragozanos en las riberas despejadas y transitables, junto a un río recuperado en el paisaje y en el entramado de acciones que producen y reproducen la vida social. De acuerdo a noticias recientes, el problema del dragado y la navegabilidad es persistente, además de la imposibilidad de llevar a cabo el proyecto de recuperación y reutilización de los edificios de los pabellones debido a la crisis financiera mundial que tuvo lugar inmediatamente después de la Expo. ${ }^{19}$

Un elemento distintivo en los discursos de la Expo Zaragoza es la conciencia de la afectación directa por parte de los participantes de El Faro y del FMLA, cuestión que los coloca en una posición de sujetos colectivos que denuncian y luchan por las reivindicaciones de estas afectaciones, a diferencia de las demandas más generales que se sitúan en el contexto menos asequible de cuestiones como el cambio climático o el desequilibrio ecosistémico.

19. La dimensión económica de la exposición es referida y analizada en el libro Los efectos económicos de la Expo Zaragoza 2008, publicado en 2009 por la Fundación Economía Aragonesa (Serrano Sanz, Gómez y Pérez y Pérez, 2009). 
Este factor es determinante para su posición respecto al aparato organizador de la Expo, y detentador del discurso dominante, ya que el tema del agua se inserta como obligado, pero no puede desvincularse discursivamente del de la sostenibilidad; ya en la realización de la Expo, la lógica estratégica se ve compelida también a incorporar presencialmente al discurso alternativo y a mostrar su propio discurso como aliado de la nueva cultura del agua. Los matices que se dan a esta última muestran, asimismo, la situación de crisis estructural planetaria que viven las formas de relación con el agua, en particular, y con los elementos de los ecosistemas, en general, establecidas a nivel mundial por parte de los actores económicamente dominantes, ya que las evidencias de las afectaciones humanas y ecosistémicas no se reconocen en las acciones y prácticas que producen y reproducen el sistema económico.

[...] hay esas inconsistencias de fondo [...] esas cosas van muy vinculadas a esta sociedad del espectáculo, a esta sociedad del consumo, pues realmente este tipo de exposiciones [son] en gran medida hijas también de eso, pues hasta qué punto pueden cometer parricidio y matar a sus orígenes para cambiar sustantivamente en base a [sic] los principios que se dicen defender, pues ahí sí que soy muy pesimista (entrevista personal, 20l lb).

Es decir, reconocer la crisis ecológica planetaria y sus consecuencias, particularmente el problema mundial del agua en esta crisis, demandaría necesariamente una transformación estructural cuyas implicaciones no son aceptables para los poderes financieros, las corporaciones multinacionales y transnacionales, y los poderes políticos de los países dominantes, ni al interior de las exposiciones ni en los espacios donde se dirimen los grandes debates globales contemporáneos. 
Tabla 1. Documentos citados del corpus de la investigación precedente

\begin{tabular}{|c|c|c|c|c|}
\hline & Documento & Fecha & Lugar & Autor(es) \\
\hline 1 & $\begin{array}{l}\text { Carta de Zaragoza } 2008 . \\
\text { http://www.expozaragoza2008. } \\
\text { es/index.jsp }\end{array}$ & $\begin{array}{l}14 \text { de } \\
\text { septiembre } \\
\text { de } 2008\end{array}$ & $\begin{array}{l}\text { Zaragoza, } \\
\text { España. }\end{array}$ & $\begin{array}{l}\text { Gobierno de } \\
\text { Aragón, BIE, } \\
\text { ONU, Tribuna del } \\
\text { Agua. }\end{array}$ \\
\hline 2 & $\begin{array}{l}\text { Tribuna del Agua. Semanas } \\
\text { temáticas, conclusiones } \\
\text { preliminares. } \\
\text { http://www.expozaragoza2008. } \\
\text { es/index.jsp }\end{array}$ & 2008 & $\begin{array}{l}\text { Zaragoza, } \\
\text { España. }\end{array}$ & $\begin{array}{l}\text { Tribuna del } \\
\text { Agua. }\end{array}$ \\
\hline 3 & $\begin{array}{l}\text { Pabellón de América Latina. } \\
\text { Bosques templados y selvas } \\
\text { tropicales. "Bajo la lluvia". } \\
\text { Catálogo oficial. }\end{array}$ & 2008 & $\begin{array}{l}\text { Zaragoza, } \\
\text { España. }\end{array}$ & $\begin{array}{l}\text { Expoagua } \\
\text { Zaragoza } 2008 .\end{array}$ \\
\hline 4 & $\begin{array}{l}\text { Catálogo General. Exposición } \\
\text { Internacional. Zaragoza } 2008 .\end{array}$ & 2008 & $\begin{array}{l}\text { Zaragoza, } \\
\text { España. }\end{array}$ & $\begin{array}{l}\text { BIE, Gobierno } \\
\text { de Aragón, } \\
\text { Ayuntamiento } \\
\text { de Zaragoza. }\end{array}$ \\
\hline 5 & $\begin{array}{l}\text { Todas las preguntas. Todas las } \\
\text { respuestas. Candidatura Expo } \\
\text { Zaragoza } 2008 .\end{array}$ & 2004 & $\begin{array}{l}\text { Zaragoza, } \\
\text { España. }\end{array}$ & $\begin{array}{l}\text { BIE, Expo } \\
\text { Zaragoza } 2008 .\end{array}$ \\
\hline 6 & $\begin{array}{l}\text { Entrevista a Francisco } \\
\text { Pellicer. }\end{array}$ & junio 2011 & $\begin{array}{l}\text { Zaragoza, } \\
\text { España. }\end{array}$ & $\begin{array}{l}\text { Entrevista } \\
\text { realizada por } \\
\text { SHL en las } \\
\text { oficinas de F. } \\
\text { Pellicer en } \\
\text { Zaragoza. }\end{array}$ \\
\hline 7 & $\begin{array}{l}\text { Revista electrónica Aqua Vitae. } \\
\text { Año 4, 2008, núm. } 6 \text {. Edición } \\
\text { especial. Expo Zaragoza: El } \\
\text { mayor evento del agua en el } \\
\text { planeta. } \\
\text { http://es.scribd.com/ } \\
\text { doc/223757850/revista- } \\
\text { aquavitae-06 }\end{array}$ & 2008 & & \\
\hline
\end{tabular}

\section{6}




\begin{tabular}{|c|c|c|c|c|}
\hline & Documento & Fecha & Lugar & Autor(es) \\
\hline 8 & $\begin{array}{l}\text { Entrevista a Pedro Arrojo. } \\
\text { Nueva Cultura del Agua. }\end{array}$ & 2011 & $\begin{array}{l}\text { Guadalajara, } \\
\text { Jal. }\end{array}$ & $\begin{array}{l}\text { Entrevista } \\
\text { realizada } \\
\text { por SHL en } \\
\text { Guadalajara, } \\
\text { Jal. }\end{array}$ \\
\hline 9 & $\begin{array}{l}\text { El Faro. Pabellón de las } \\
\text { Iniciativas Ciudadanas. } \\
\text { Sitio Fundación Ecología y } \\
\text { Desarrollo. }\end{array}$ & 2008 & $\begin{array}{l}\text { Zaragoza, } \\
\text { España. }\end{array}$ & $\begin{array}{l}\text { Fundación } \\
\text { Ecología y } \\
\text { Desarrollo. }\end{array}$ \\
\hline 10 & $\begin{array}{l}\text { Memorias del Pabellón de } \\
\text { Iniciativas Ciudadanas El } \\
\text { Faro. }\end{array}$ & & $\begin{array}{l}\text { Zaragoza, } \\
\text { España. }\end{array}$ & $\begin{array}{l}\text { Víctor Viñuales, } \\
\text { editor, de } \\
\text { Ecología y } \\
\text { Desarrollo. }\end{array}$ \\
\hline 11 & $\begin{array}{l}\text { I Foro Mundial de las Luchas } \\
\text { del Agua. } \\
\text { http://www.FNCA.eu/ } \\
\text { congresoiberico/index } 2 \text {. } \\
\text { php?lan=1\&pag=3\&com=4 }\end{array}$ & $\begin{array}{l}4-7 \\
\text { diciembre } \\
2008\end{array}$ & $\begin{array}{l}\text { Zaragoza, } \\
\text { España. }\end{array}$ & $\begin{array}{l}\text { Marisancho } \\
\text { Menjón. } \\
\text { Congreso Ibérico } \\
\text { sobre Gestión y } \\
\text { Planificación del } \\
\text { Agua. }\end{array}$ \\
\hline & $\begin{array}{l}\text { Líderes sociales de todo el } \\
\text { mundo en la lucha por el agua } \\
\text { mostrarán en Zaragoza "la } \\
\text { otra verdad que no se ve en } \\
\text { la Expo". } \\
\text { http://foroluchasagua. } \\
\text { wordpress.com/ }\end{array}$ & $\begin{array}{l}23 \text { de junio } \\
\text { de } 2008\end{array}$ & & $\begin{array}{l}\text { Blog Foro } \\
\text { Mundial por } \\
\text { las Luchas del } \\
\text { Agua. }\end{array}$ \\
\hline 12 & $\begin{array}{l}\text { Desenmascaremos Zaragoza } \\
2008 . \\
\text { Obtenido en: } \\
\text { httwww.lagarbancitaecologica. } \\
\text { org/garbancita/index. } \\
\text { php/tecnologias-y- } \\
\text { contaminacion?start=9 }\end{array}$ & Junio 2008 & $\begin{array}{l}\text { Madrid, } \\
\text { España. }\end{array}$ & $\begin{array}{l}\text { GAK } \\
\text { (Grupos } \\
\text { Autogestionados } \\
\text { de Konsumo). }\end{array}$ \\
\hline
\end{tabular}

Fecha de recepción: 18 de agosto de 2014

Fecha de aceptación: 18 de agosto de 2015 
Bibliografía
Andersen, N. A. (2003). Discursive analytical strategies. Glasgow, Gran Bretaña: The Policy Press.

Belloch, J. A. (2008). "Prólogo", en, Pabellón de América Latina. Bosques templados y selvas tropicales, "Bajo la Iluvia” (p. 9). Zaragoza: Expoagua Zaragoza 2008/Prensa Diaria Aragonesa.

B. I. E. (s/f). The 1928 Paris Convention. Recuperado de: http:// www.bie-paris.org/site/images/stories/files/BIE_Convention_eng.pdf.

— y Expo Zaragoza 2008 (2008). Carta de Zaragoza 2008. Recuperado de: http://www.expozaragoza2008. es/pdf/cartazgz-es.pdf

Bureau International des Expositions (2004). Todas las preguntas. Todas las respuestas. Candidatura Expo Zaragoza 2008. Zaragoza: Zaragoza Expo 2008.

Castro, C. (ed.) (2009). Pabellón de iniciativas ciudadanas EI Faro. Memorias. Zaragoza: Calidad Gráfica Araconsa.

Castro, E. (2004). El vocabulario de Michelle Foucault: un recorrido alfabético por sus temas, conceptos y autores. Buenos Aires: Universidad Nacional de Quilmes, Prometeo.

COAGRET (s/f). Qué es COAGRET. Recuperado de: http://www. coagret.com/quienes-somos?showall=\&limitstart=

Ecodes (s/f). El Faro: Pabellón de las Iniciativas Ciudadanas. Recuperado de: http://ecodes.org/agua-y-ecodes/ el-faro-pabellon-de-iniciativas-cuidadanas.

Expoagua Zaragoza 2008 (2008). Catálogo General. Exposición Internacional Zaragoza 2008. España: Turner.

Exposición Internacional Zaragoza 2008 (2008). Expo Zaragoza 2008. Recuperado de: http://www.expozaragoza2008.es/index.jsp

Findling, J. E. (2008). Encyclopedia of World's Fairs and Expositions. Carolina del Norte, EE. UU.: McFarland and Company.

Foro Mundial de las Luchas del Agua (2008). Líderes sociales de todo el mundo en la lucha por el agua mostrarán en Zara- 
goza "la otra verdad que no se ve en la Expo". Recuperado de: https://foroluchasagua.wordpress.com/2008/06/23/ lideres-sociales-de-todo-el-mundo-en-la-lucha-porel-agua-mostraran-en-zaragoza-\%E2\%80\%9Cla-otraverdad-que-no-se-ve-en-la-expo\%E2\%80\%9D/

Foucault, M. (1980). "The confession of the flesh: a conversation”, en C. Gordon (ed.), Power/knowledge, selected interviews and other writings, Michael Foucault (pp. 128). Nueva York: Pantheon Books.

(2009). Vigilar y Castigar. México: Siglo XXI Editores. (20I0). La arqueología del saber. México: Siglo XXI Editores.

Fundación Nueva Cultura del Agua (s/f). Fundación Nueva Cultura del Agua. Recuperado de: http://www.fnca.eu/ mision-y-valores

Giddens, A. (2002). Consecuencias de la modernidad. Madrid: Alianza Editorial.

González Loscertales, V. (20I2). "World Expos open the door to the future". World Finance. Recuperado de: http://www.worldfinance.com/inward-investment/ world-expos-open-the-door-to-the-future

Greenhalgh, P. (20II). Fair World. A history of World's Fairs and Expositions. From London to Shanghai I85I-20I0. Berkshire, Reino Unido: Papadakis.

Herrera Lima, S. (20I la). Entrevista personal a F. Pellicer. Zaragoza, España.

(20I Ib). Entrevista personal a P. Arrojo. Guadalajara, México.

(20I3). De la comunicación del progreso a la comunicación de la armonía. Las transformaciones en los discursos sobre las relaciones sociedad/naturaleza en el escenario de las Exposiciones Universales (I85I-20I0) (tesis de maestría inédita). Estudios Socioculturales, ITESO: Guadalajara, Jalisco. 
Bibliografía
(20I5). Del progreso a la armonía. Naturaleza, sociedad y discurso en las Exposiciones Universales (I893-2019). Guadalajara: ITESO (en prensa).

Jäger, S. (2003). "Discurso y conocimiento: aspectos teóricos y metodológicos de la crítica del discurso y del análisis del dispositivo", en W. Ruth (comp.), Métodos de análisis crítico del discurso (pp. 6I-100). Barcelona: Gedisa.

La Garbancita Ecológica (2008). Desenmascaremos Zaragoza. Recuperado de: http://www.lagarbancitaecologica.org/garbancita/index.php/economia-sociedadnaturaleza/ /43-desenmascaremos-zaragoza-2008

Martínez Deaño, N. (ed.) (2008). Catálogo General. Exposición Internacional Zaragoza 2008. España: Turner.

Menjón, M. (2008). "I Foro Mundial de las Luchas del Agua, celebrado en Zaragoza: el compromiso con los afectados". Memorias del Congreso Ibérico sobre Gestión y Planificación del Agua. Recuperado de: http://www.fnca. eu/congresoiberico/index2.php?lan= I \&pag= I

Naciones Unidas (s/f). Biblioteca Dag Hammarskjöld de las Naciones Unidas. Recuperado de: http://www.un.org/ depts/dhl/spanish/resguids/specenvsp.htm

Nicolau lbarra, J. M. (2000). "Problemática ambiental de los embalses en el Pirineo Aragonés". Revista de Estudios Territoriales del Pirineo Aragonés, (2). Recuperado de: http://www.yesano.com/informes/nico_estudios_territoriales.html

Revista Aqua Vitae (2008a). "Entrevista a Pedro Arrojo: Las organizaciones sociales aportan denuncia vitalidad y alternativas". Revista Aqua Vitae, 4(6). Recuperado de: http://es.scribd.com/doc/223757850/revista-aquavitae-06

(2008b). "Entrevista a Eduardo Mestre: Expo Zaragoza tiene que entregar resultados concretos al 
mundo”. Revista Aqua Vitae, 4(6). Recuperado de: http:// es.scribd.com/doc/223757850/revista-aquavitae-06

Rydell, R. (1984). All the world's a fair. Chicago: The University of Chicago Press.

(1993). World of fairs. Chicago: University of Chicago Press.

Serrano Sanz, J. M., Gómez, A., y Pérez y Pérez, L. (2009). Los efectos económicos de la Expo Zaragoza 2008. Zaragoza: Fundear.

Tenorio Trillo, M. (1996). Artilugio de la nación moderna. México en las exposiciones universales, 1880-1930. México: Fondo de Cultura Económica.

Tribuna del Agua (2008). Tribuna del agua. Semanas temáticas, conclusiones preliminares. Recuperado de: http://www. expozaragoza2008.es/index.jsp

Wallerstein, I. (20I I). "El capitalismo moderno ha llegado al final de la cuerda. Entrevista con Immanuel Wallerstein". Observatorio Latinoamericano de Geopolítica. Recuperado de: http://www.geopolitica.ws/media/uploads/el_capitalismo_moderno_ha_llegado_al_final_de_la_cuerda.pdf

Bibliografía 